\title{
CRÓNICA DEL I CONGRESO INTERNACIONAL DE DERECHO PROCESAL TITULADO "POSTMODERNIDAD Y PROCESO EUROPEO: EL PRINCIPIO DE OPORTUNIDAD EN EL ÁMBITO DE LA RESPONSABILIDAD DE LAS EMPRESAS"
}

\author{
Juan Manuel Alonso Furelos \\ Profesor Titular de Universidad de Derecho Procesal \\ Universidad Nacional de Educación a Distancia. U.N.E.D.
}

Recepción original: 02/09/2019

Aceptación original: 07/10/2019

Los días 6 y 7 de Mayo del presente año 2019, en sesiones matinales tuvo lugar en el edificio del Colegio Universitario Villanueva de Madrid la celebración del I Congreso Internacional de Derecho Procesal titulado "Postmodernidad y Proceso Europeo: el principio de oportunidad en el ámbito de la responsabilidad penal de las empresas" al que fui invitado expresamente por la Dra. Dña. Sonia Calaza López y a la que posteriormente ofrecí hacer la crónica del mismo, para que no quedara en el silencio u olvido o al menos hacer más difícil dicho olvido y silencio, a lo que accedió gustosamente. Dicha crónica que para mí fue un honor plasmarla, eso sí más o menos resumida, es el resultado de las sesiones descritas que conforman el Congreso.

Dña. Sonia Calaza López es Catedrática de Universidad (C.U.) de Derecho Procesal de la UNED, directora del Departamento de Derecho Procesal de la UNED y codirectora de este Congreso. Lo es junto al también codirector D. José Carlos Muinelo Cobo profesor Titular de Universidad (T.U) de Filosofía Jurídica y ambos codirectores 
en representación de la UNED. También es codirectora de este congreso Dña. Mercedes de Prada Rodríguez a su vez directora del Área de Derecho del Colegio Universitario (C.U) Villanueva de Madrid al que representa en este Congreso.

Está organizado este Congreso por la Universidad Nacional de Educación a Distancia (U.N.E.D.), el Colegio Universitario Villanueva de Madrid y la Universidad Pontificia de Comillas. I.C.A.D.E.

Dicho Congreso se celebra en el marco del Proyecto de Excelencia I+D+I titulado "Postmodernidad y proceso: la oportunidad como principio informador del proceso judicial" del Ministerio de Economía y competitividad con REF. DER. 2017-87144-P desde el 1 de Enero de 2018 hasta el 31 de Diciembre del 2020. Son investigadores principales del citado proyecto los profesores Dña. Sonia Calaza López Catedrática de Derecho Procesal de la UNED y D. José Carlos Muinelo Cobo Profesor Titular de Filosofía del Derecho de la UNED y codirector de dicho Congreso.

Nadie puede dudar de la importancia que tiene un Congreso Internacional con la participación de ponentes de Universidades extranjeras y los distintos puntos de vista que ofrecen abordando instituciones jurídicas de derecho comparado y su ámbito diferencial con las instituciones jurídicas españolas.

Pero tampoco es desdeñable el dicho de que la "unión hace la fuerza" y así recalco de nuevo que la organización de este Congreso está a cargo de tres instituciones Universitarias cuales son la UNED, la Universidad Pontificia de Comillas I.C.A.D.E. y el Colegio Universitario (Universidad) Villanueva de Madrid. Además, debe destacarse que la UNED es una Universidad pública, mientras que ComillasICADE y el C.U. Villanueva de Madrid son privadas.

De la simbiosis entre lo público y privado, y su comparación, siempre resultan aspectos novedosos, diferentes, en suma, importantes y de gran interés lo que entiendo debe ser destacado.

Se une a ello que estamos ante un $\mathrm{I}+\mathrm{D}+\mathrm{I}$ Ministerial, donde previamente a la dotación de los fondos que lo hagan posible existe un control de su calidad, interés, vicisitud y relevancia tanto desde el plano económico, social como el de la excelencia a que responde o debe responder la investigación científica universitaria, de ese tipo.

Los ponentes como después destacaremos son destacados, sobresalientes, de reconocido prestigio, si bien como ocurre en todo Congreso unos son más conocidos que otros, lo que no es óbice a la gran calidad de sus Ponencias y a que por virtud de su participación en 
Congresos Internacionales su prestigio se va acentuando más con el paso del tiempo. ción:

El día 5 de Mayo, según lo previsto, hubo dos mesas de interven-

La primera de 10 a 12 horas, con cuatro intervenciones. Fueron las que siguen:

Dña. Katharina Beckemper Catedrática de Derecho Penal y Procesal Penal de la Universidad de Leipzig y su ponencia versó sobre "El principio de oportunidad en el proceso penal alemán por deudas económicas"; D. Luis Lafont Nicuesa, Fiscal adscrito al Fiscal de Sala coordinador de extranjería de la Fiscalía del Estado y su ponencia referida a "La negociación en el derecho penal económico"; Dña. Alicia González Navarro, profesora Titular de Derecho Procesal de la Universidad de La Laguna y su ponencia dedicada a "La proyección trasversal del principio de oportunidad en los procesos civil y penal"; y Dña. Verónica López Yagüe, profesora Titular de Derecho Procesal de la Universidad de Alicante y su ponencia versó sobre el "Principio de oportunidad y enjuiciamiento de los delitos leves"

Moderó esta primera mesa Dña. Mercedes de la Prada Rodríguez, Directora del Área de Derecho del Colegio Universitario Villanueva.

La segunda mesa desde las 12,15 horas a las 14,30 con dos intervenciones (de las tres previstas en principio pues excusó su asistencia D. Agustín Jesús Pérez-Cruz Martín, Catedrático de Derecho Procesal de la Universidad de Oviedo y cuya ponencia habría versado sobre "Uso y abuso de la oportunidad penal"). Fueron las que siguen:

Excmo. Sr. D. Jacobo Borja de Quiroga Magistrado del Tribunal Supremo cuya ponencia versó sobre "El principio de oportunidad en el ámbito penal: cuestiones generales"; D. Nicolás Rodríguez García, Catedrático de Derecho Procesal de la Universidad de Salamanca y su ponencia dedicada a "Negociaciones y acuerdos en los procesos penales por corrupción”.

Moderó Dña. Sonia Calaza López, Catedrática de Derecho Procesal de la Universidad Nacional de Educación a Distancia (U.N.E.D).

El día 6 de Mayo por la mañana, hubo nuevamente otras dos mesas de intervenciones.

La primera de 10 a 12 donde hubo cuatro intervenciones, las que siguen por este orden: 
Dña. María Burzaco Samper, Profesora Agregada de Derecho Administrativo de la Universidad Pontificia de Comillas ICADE defendiendo con su ponencia "El principio de oportunidad en el proceso contencioso administrativo: sus posibilidades y limitaciones"; Dña. Marta Gisbert Pomata, Profesora Agregada de Derecho Procesal de la Universidad Pontificia de Comillas ICADE y su ponencia versó sobre "El papel de los jueces en la solución negociada de los conflictos civiles: la mediación interjudicial"; Dña. Dolores Carrillo Márquez, Profesora Agregada del Derecho del Trabajo y de la Seguridad Social, cuya ponencia la dedicó a "Reflexiones sobre la aplicación del principio de oportunidad en la resolución de conflictos en el marco del contrato de trabajo"; y Dña. Corazón Mira Ros, Letrada del Tribunal de Cuentas y Profesora Titular de Derecho Procesal de la UNED y su ponencia referida a la "La conformidad con la pena y los principios constitucionales. ¿Es siempre válida la renuncia al derecho de defensa?"

Moderó D. Guillermo Ruiz Blay, Abogado.

La segunda mesa de 12,15 a 14,15 horas, conto con tres intervenciones:

Dña. Sara Díez Riaza, Profesora Ordinaria de Derecho Procesal de la Universidad Pontifica de Comillas ICADE con su Ponencia "Mecanismos alternativos al ejercicio del ius puniendi y la desjudicialización de la intervención con los menores"; Dña. Ana Luaces Gutiérrez, Profesora Titular de Derecho Procesal de la UNED cuya Ponencia versó sobre "Proceso de aceptación por Decreto y principio de oportunidad"; y D. Carlos Vázquez González, Profesor Titular de Derecho Penal de la UNED cuya ponencia dedicó al "Principio de oportunidad policial en el proceso penal anglosajón".

Moderó el Excmo. Sr. D. Manuel Martínez de Aguirre, Fiscal del Tribunal Supremo.

Antes de entrar en la intervención resumida de cada Ponente, con la que proseguiremos después esta Crónica, creo que es el momento de destacar:

PRIMERO. Pese al título de este Congreso Internacional "El principio de oportunidad en el ámbito de la responsabilidad penal de las empresas" el objeto de muchas Ponencias excede ese ámbito, lo cual entiendo resulta positivo. En efecto las intervenciones de Dña. Alicia González Navarro, Dña. María Burzaco Semper, Dña. Marta Gisbert Pomata y Dña. Dolores Carrillo Márquez se centraron en el ámbito del principio de oportunidad en los otros órdenes juris- 
diccionales distintos del penal, es decir en el orden civil del proceso (sea su objeto civil, mercantil o internacional privado), en el orden contencioso administrativo (proceso administrativo) y en el orden social (proceso laboral).

SEGUNDO. Hubo intervenciones que si bien referidas al principio de oportunidad en el proceso penal no se refieren al derecho penal económico y de la responsabilidad penal de las empresas (personas jurídicas, por lo tanto) en dicho ámbito, sino que lo hacen de forma más general en el proceso penal. Así las intervenciones de Dña. Verónica López Yagüe referida al proceso por delitos leves exclusivamente; y en igual medida la de Dña. Ana Luaces Gutiérrez también dedicada a estos. La de Dña. Sara Díez Riaza está referida al principio de oportunidad en el proceso de menores. Y la de D. Carlos Vázquez se refiere al principio de oportunidad de la Policía inglesa consistente en no denunciar al Fiscal las infracciones cometidas por primera vez por menores de leve entidad penal si muestran su arrepentimiento e inmediatamente tratan de reparar las consecuencias del delito, manifiestan que no volverán a repetirlo, no sean reincidentes y con la intervención de sus padres o representantes legales que se comprometen a que no se repita.

Incluso la ponencia más concreta de D. Nicolás Rodríguez García referida a los procesos penales por corrupción puede ser incluida, o no, dentro de la responsabilidad penal de las empresas por delitos económicos, según su actuar delictivo tenga o no su origen en la corrupción. Lo mismo sucede con la ponencia del Excmo. Sr. D. Jacobo Borja de Quiroga referida a cuestiones generales del principio de oportunidad (e históricas sobre su origen).

Propiamente dentro del título del Congreso pueden señalarse las ponencias de Dña. Katharina Beckemper, referida al principio de oportunidad en el proceso penal alemán por delitos económicos (y que suele afectar a las personas jurídicas si son parte pasiva) y la de Luis Lefont Nicuesa sobre la negociación en el Derecho penal económico, por tanto, referida a personas físicas o jurídicas en cuanto partes pasivas del proceso penal.

TERCERO. Definir lo que es el principio de oportunidad, en lo que es común al derecho procesal y al derecho material, por su amplitud, resulta difícil. Quizá por ello los ponentes hayan renunciado a definirlo limitándose a enunciarlo y desarrollarlo en supuestos concretos, en las manifestaciones de sus ponencias en este Congreso. Incluso, es variopinto a la luz del resultado en los derechos comparados. 
En este sentido es de destacar a Dña. Katherina Beckemper, cuando afirma al defender su ponencia que el principio de oportunidad en el proceso penal alemán (y derecho penal alemán) no es asimilable, por sus diferencias, con el previsto en el sistema procesal español. Así, el principio de oportunidad puede -o no- contraponerse con el principio de legalidad penal y procesal penal.

Así en el ámbito material de la pena (o ius puniendi). $\mathrm{O}$ en el ámbito procesal, en este caso respecto a su posible inicio, o no inicio, por el Ministerio Fiscal en los delitos sujetos a procedibilidad o perseguibilidad pública siempre dentro de las amplias facultades del Fiscal en cuanto director de la instrucción o sumario; o para sí una vez iniciado debe proseguir normalmente hasta su fin en el proceso (sentencia común) o por el contrario es posible una finalización anormal y anticipada del proceso con una resolución de fondo equivalente a una sentencia de conformidad, es decir consensuada, entre las partes actoras y pasivas; e incluso con una resolución a propuesta del Fiscal que no se pronuncie sobre el fondo de sostener éste la procedencia del archivo de las actuaciones, o lo que es lo mismo, su materialización en un sobreseimiento libre o provisional.

Pero también dese el plano material y procesal la sentencia consensuada lleva consigo que no sea posible su ulterior impugnación por los medios ordinarios (el acuerdo es la antítesis al gravamen presupuesto de todo recurso). También la sentencia penal indeterminada o condicionada (Véase la magnífica monografía, para su tiempo, de Luis Jiménez de Asúa, la sentencia indeterminada, Madrid 1914) una vez firme puede ser concretada o determinada dependiendo de ulteriores conductas del condenado a la hora de determinar la forma del cumplimiento de las penas o el tiempo de su duración.

El principio de oportunidad suele contraponerse con el de legalidad (penal y procesal), aunque el principio de oportunidad reglado (es decir legislado bajo la garantía de una Ley Orgánica, es por ello una opción legal) puede suponer un camino intermedio entre ambos principios de legalidad y oportunidad. Así la discrecionalidad dentro de los parámetros permitidos por el principio de oportunidad se encuentra limitada por dicha auto regulación siempre que no permite en ningún caso la arbitrariedad, que siempre debe estar prohibida sobre todo en el ámbito penal en tanto en cuanto lo contrario vulneraría el propio sistema constitucional y toda manifestación del principio de seguridad jurídica consecuencia de la legalidad. Por tanto, discrecionalidad con los límites reglados del principio de oportunidad sin que en ningún caso se ampare la arbitrariedad. 
CUARTO. Al margen de su autocontrol legal (que supone la regulación de la oportunidad, dentro de ciertos parámetros de discrecionalidad sea o no técnica) el principio de oportunidad se presenta como un principio social a seguir por razones de conveniencia, pertinencia, adecuación, futura política procesal, o utilidad social.

En el plano procesal, la oportunidad es un principio social de utilidad en tanto en cuanto puede servir para descargar a nuestros juzgados y tribunales del exceso de trabajo acumulado por múltiples causas. Así impidiendo el nacimiento de procesos, facilitando la terminación anormal y extraordinaria de los ya iniciados e incluso impidiendo las instancias sucesivas de los que su sentencia no es todavía firme o permitiendo que el consenso o la conformidad entre las partes las haga firmes e irrecurribles anticipadamente desde ese momento por no existir gravamen.

Ahorro de gastos (los que sufraga el Estado y determina en sus Presupuestos) a los juzgados y tribunales y de tiempo (por descarga de trabajo en los trámites procesales que se evitan). Y a las propias partes (por la reducción del coste que supone la intervención de abogados y procuradores en dichos trámites, aunque éstos por suerte no suelen quejarse del exceso de trabajo acumulado en sus despachos). Todo desde el plano económico.

También se descargaría de trabajo a nuestros juzgados y tribunales (principio de oportunidad) si se permitiera a los jueces y magistrados ya jubilados que sin perjuicio del cobro íntegro de su pensión pudieran seguir desempeñando la jurisdicción, abonándoseles una retribución por cada proceso resuelto, semejante a la resultante de la minuta del abogado de cada parte y que estuviera exenta esa retribución del pago del IRPF y en caso de justicia gratuita fuera semejante a la retribución ofrecida al abogado.

QUINTO. Desjudicializar asuntos civiles, laborales, contenciosos administrativos de muy escasa cuantía (pensemos de menos de 100 $€$ y que sólo puedan ser decididos por medios alternativos al proceso incluido el arbitraje; o en la segunda instancia exigiendo una "suma gravaminis" cuantitativa, o un gravamen cualitativo en atención a su objeto.

O los procesos penales por delitos muy leves o "de bagatela", y de escasa repercusión social, o poca frecuencia que no crean alarma social a las víctimas y las penas son leves. O que la desjudicialización venga condicionada o determinada por la inmediata reparación del daño causado a la víctima antes del inicio del proceso. 


\section{ASPECTOS DESTACADOS EN CADA PONENCIA.}

\section{DÑA. KATHERINA BECKEMPER. (Catedrática de Derecho Penal y Procesal penal de la Universidad de Leipzig). EL PRINCIPIO DE OPORTUNIDAD EN EL PROCESO PENAL ALEMÁN POR DELITOS ECONÓMICOS.}

Destacó que los principios de legalidad y oportunidad son entendidos de forma diferente en Alemania y en España. Ello es consecuencia de que en Alemania la acción penal en todo caso es pública (principio de legalidad), compete al Ministerio Fiscal y éste es el director de la investigación sumarial. El principio de oportunidad en Alemania busca sobre todo acelerar el procedimiento penal alemán y que este termine anticipadamente en caso de un acuerdo entre el Fiscal, el abogado de la parte pasiva y el juez decisor del proceso penal. En España sin embargo la acción en delitos públicos no es exclusiva del MF, y el Fiscal no es el director de la investigación o sumario si no el Juez de Instrucción.

En el proceso penal alemán el principio de oportunidad no está ligado a si procede iniciar o no un proceso penal, ni supone reconocer los hechos, si no que anticipa la sentencia penal incluso evitando el juicio oral. La pena en caso de un acuerdo anticipado en los delitos de escasa gravedad y de la inmediata reparación o arrepentimiento puede estar condicionada o ser sustituida por otra a la prevista en la ley penal o después durante su cumplimiento.

En los delitos económicos, en Alemania, la conformidad o acuerdo (sobre la pena de contenido económico) entre Fiscal, abogado del acusado y el Juez está sujeta a un fuerte control del Estado dado el interés público del Estado y ello puede suponer un riesgo a que se "comercialice" el proceso penal y el derecho penal en el caso que el Estado "ceda" ante el acuerdo logrado entre los operadores jurídicos si el importe de la pena económica es cuantioso, y a "cambio" de otras penas no privativas de libertad.

Tanto si la parte pasiva es una persona física para evitar las penas privativas de libertad personal, como cuando es una persona jurídica y evitar su disolución (y buscando que su abogado defensor no sea el mismo que se ocupe de la defensa de sus administradores o representantes legales debiendo actuar los letrados respectivos en ese proceso penal por separado). Evitar pues que el acusado compre su libertad pagando penas económicas o la persona jurídica así evite su disolución en virtud de la causa penal. 
También abordó si es mejor un modelo penal y de procesal penal en el que las personas jurídicas tengan o no capacidad para delinquir (si pueden o no ser parte pasiva) sin perjuicio de su disolución (es decir, delinquir sólo sus administradores o representantes legales o por el contrario las personas jurídicas pueden delinquir y ser parte pasiva en el proceso penal aunque en tal caso diferenciándose su actuación como parte pasiva (defendidas por otro abogado, procurador y un defensor legal expresamente nombrado al efecto), de la actuación también como parte pasiva, en ese proceso penal, de sus administradores o representantes legales (defendidos y representados por otros abogados y procuradores). Todo sin olvidar que en el ámbito de los delitos económicos es frecuente que las personas jurídicas sean parte pasiva.

\section{D. LUIS LAFONT NICUESA. (Fiscal adscrito al Fiscal de Sala coordinador de extranjería de la Fiscalía General del Estado). LA NEGOCIACIÓN EN EL DERECHO PENAL ECONÓMICO.}

Destacó en su comunicación que el papel del Fiscal en nuestro sistema nada tiene que ver con el modelo americano pues es mucho menos relevante ya que el sumario está bajo la dirección del juez instructor (sea ordinario o especial) y el Fiscal en España no puede decidir si inicia o no el proceso penal con base en el principio de legalidad, ni tiene decisión unilateral para archivar o no las actuaciones sumariales.

A diferencia del modelo americano, donde el papel del Fiscal en la investigación de los hechos delictivos y en especial en los económicos es fundamental e incluso determinante para iniciar el proceso penal o no, o para su prosecución o ponerle fin de forma extraordinaria, así como para la determinación de las penas y medidas de prevención o alternativas que procedan y a su imposición en caso de acuerdo con el abogado de la parte pasiva. En este caso, dependiendo del papel de la parte pasiva para remediar, limitar o incluso impedir los efectos colaterales del delito. (Pronta restitución, reparación, e indemnización, arrepentimiento inmediato, no exista reincidencia, medidas de prevención generales o especiales ya individuales o sociales, medidas evitando daños colaterales, medidas de aseguramiento o seguridad, que eviten los efectos o consecuencias perjudiciales de forma inmediata a las víctimas o que sin serlo sean personas afectadas por el delito, permitir o limitar la publicidad negativa 
del delito, pago inmediato de multas, colaborar con el Fiscal en su descubrimiento...)

Y en el caso de los delitos económicos son todavía menores en España las facultades del Fiscal por lo dicho, sin perjuicio de la información que puede proporcionarle en el sumario o juicio oral la Fiscalía en especial la de la Audiencia Nacional (caso de delitos económicos de ámbito nacional) o la propia Fiscalía General del Estado.

Incluso en el juicio oral es el órgano jurisdiccional quien acoge o no en España los posibles acuerdos entre el abogado del acusado y el Fiscal dentro de los límites (legales) que este tiene para proponerlos dentro de lo que el principio de oportunidad (reglado, por tanto) permite. Nada que ver con el modelo americano donde el papel del Fiscal es determinante para el acuerdo con el letrado de la parte pasiva.

Incide también la reforma operada por el vigente Código Penal, respecto al anterior, en cuanto a la capacidad delictiva de las personas jurídicas y por tanto para actuar como parte pasiva en un proceso penal admitido en el vigente y negada en el anterior, sin perjuicio que la disolución de la persona jurídica hoy se admita como una pena impuesta a estas y en el anterior código como un efecto jurídico consecuencia de la sentencia que condenaba a sus administradores o representantes legales.

Por tanto, al amparo del vigente $\mathrm{CP}$ esto se verá reflejado en que es admisible la imposición de penas (y medidas de seguridad) múltiples a las personas jurídicas; y que se tengan que constituir como parte pasiva asistidas de abogado, representadas por procurador y que se les nombre un defensor (legal) judicial (que supla la capacidad procesal de actuar en juicio) cuando los administradores o sus representantes legales sean parte pasiva en ese proceso penal para la defensa de los intereses contrapuestos.

Cosa diferente y que varía según los sistemas legales del derecho comparado es como decimos si el procurador y abogado antes mencionado puede ser común a la persona jurídica y sus representantes o administradores en ese "macrojuicio" al menos respecto a las partes pasivas o debe ser diferente de cara a una mayor tutela del derecho de defensa de la persona jurídica. (art. $24 \mathrm{CE}$ ). 


\section{DÑA. ALICIA GONZÁlEZ NAVARRO (Prof. TU. Derecho Procesal. Universidad de la Laguna). PROYECCIÓN TRASVERSAL DEL PRINCIPIO DE OPORTUNIDAD EN LOS PROCESOS CIVIL Y PENAL.}

Considera que puede hablarse de una proyección trasversal del principio de oportunidad en los procesos civil y penal y respecto a este último una manifestación es el caso de los delitos privados.

Desde esta perspectiva propugna la supresión, del Código penal, de los delitos privados de injurias y calumnias. Y que su tramitación procesal, para reclamar la indemnización económica se haga por el cauce procesal civil de los delitos contra el honor (intimidad y propia imagen).

Considera que las injurias y calumnias atentan el derecho (fundamental) del honor y este podría ser el cauce procesal especial en proceso civil que ofrece una tutela rápida para pedir la indemnización económica en caso de ser vulnerado. El cauce del proceso penal por delito privado quedaría así vaciado de contenido, con su despenalización.

Esto sin olvidar que en el proceso civil especial (rápido) para la defensa del derecho al honor es siempre parte el Ministerio Fiscal, en todo caso. Y puede tener un papel relevante en la defensa de ese derecho vulnerado como es el honor. Y respecto a la parte que sufre esa vulneración puede ayudarla así en la defensa de ese derecho (junto a la defensa por el MF, además del interés general, y la legalidad) y especialmente cuando se trate de menores, incapaces, ausentes o personas desvalidas. Ello, a diferencia con el proceso penal por delitos privado en que no es parte el Fiscal y cabe la renuncia a la acción penal en dichos delitos (sin límite) por el perjudicado, lo que hace que su posición sea más frágil en el proceso penal por delito privado.

Además, en el proceso penal por delitos sujetos a procedibilidad privada, el objeto del proceso se deduce íntegramente en la querella y tras ella se confirma (y conforma) en las calificaciones provisionales a diferencia con los delitos sujetos a procedibilidad pública o semipública. Por tanto, la querella privada guardaría paralelismo con la demanda en el proceso civil especial referido a la tutela del derecho al honor.

Destacó, además, que sí el proceso penal por delito privado se inicia por alguna de las víctimas de la injuria o calumnia y resultase condenada la parte pasiva, en virtud de los hechos probados consti- 
tutivos de tales delitos (por tanto identidad subjetiva pasiva penal e identidad objetiva penal), la sentencia penal condenatoria debería producir los efectos de la cosa juzgada respecto a las futuras y posibles partes actoras privadas afectadas que no se constituyeron como parte en ese proceso penal por delito privado en su momento (no estaban obligadas a ello). Ello es así porque la cosa juzgada penal afecta a la parte pasiva condenada por esos hechos probados constitutivos del delito de injuria o calumnia y extiende sus efectos (positivos o prejudiciales) a las futuras partes pasivas que no se constituyeron en parte en su momento. (No entramos en la complejidad de la cuestión de la cosa juzgada en los delitos privados y si debe o no defenderse esta posición).

Se refiere en su ponencia a las injurias y calumnias privadas contra los particulares, exclusivamente. Quedan fuera las que lo sean contra los funcionarios, de carácter público. Excluye también las vertidas en juicio y que necesitan autorización del juez competente del proceso o juicio en que se vierten para iniciar un proceso penal. Y excluye también las vertidas en el Congreso o Senado, contra Diputados y Senadores nacionales (en los autonómicos debe estarse al respectivo Estatuto de Autonomía) y por personas que tengan tal condición, pues se requiere para ello la autorización de la Cámara respectiva o Suplicatorio. Para estos supuestos seguiría siendo de aplicación el régimen vigente.

Respecto al proceso penal seguido contra las personas jurídicas, señala que, es preciso un desarrollo normativo y cualquiera que fuera debería ser objeto de un proceso específico.

\section{DÑA. VERónICA LóPEZ YAGÜE. (Prof. TU. Derecho Procesal. Universidad de Alicante). PRINCIPIO DE OPORTUNIDAD Y ENJUICIAMIENTO DE DELITOS LEVES.}

Comenzó destacando que, aunque pueda parecer que la destipificación de las faltas supondría que los delitos leves pasarían a ser pocos y residuales, no fue así. Es cierto que, destipificar las faltas, supone engrosar los ilícitos civiles y administrativos, pero no podemos olvidar que algunos supuestos de faltas agravadas del anterior $\mathrm{CP}$, tras la última reforma legal, han pasado a ser delitos leves. De la misma forma que figuras antes no tipificadas como delitos han pasado a ser delitos leves.

Considera que las funciones del Fiscal en los delitos leves deben ser más amplias en la fase de instrucción si se encarga de su direc- 
ción exclusiva, aunque esto está pendiente de una futura reforma legal y del papel que al final se le encomiende en el sumario (en detrimento del juez instructor actualmente director de la investigación sumarial).

Propugna respecto a los delitos leves que se evite en lo posible el exceso de litigiosidad, propugnando la potenciación del principio de intervención mínima en materia penal a que debe responder el derecho penal y el proceso penal y que dentro de este parámetro se amplíen las facultades del fiscal que podrían estar regladas en la LECRIM dentro del principio de oportunidad. Igualmente, propugna la potenciación de la conformidad penal en los delitos leves y sustituir las penas privativas o restrictivas de libertad, o de otros derechos, en los delitos leves, por multas o el trabajo en beneficio de la comunidad. Incluso que no se abra el proceso penal si se llega a la conformidad entre la futura parte pasiva y el Fiscal respecto a la multa o el trabajo en beneficio de la comunidad.

También se plantea, si el procedimiento actual para enjuiciar los delitos leves, que era el antes vigente para las faltas (hoy destipificadas), con ligeros retoques de la última reforma de la LECRIM es el más adecuado o por el contrario debe incidirse en una regulación sobre todo en la fase anterior a la del juicio (donde no existan manifestaciones formales del sistema acusatorio) para que el Fiscal pueda utilizar mejor esas hipotéticas facultades en el caso que le sea encomendada exclusivamente la investigación del sumario.

Defiende que en estos delitos la competencia (objetiva y funcional) para fallar en la primera instancia debe corresponder al Juez de Instrucción como se prevé y no al Juez de Paz y en cualquiera de sus tres modalidades: la ordinaria y las dos aceleradas. Aunque también deben tener competencia los Juzgados de Guardia en muchos supuestos para investigar estos delitos (Art.962 a 964 LECRIM). (Quizá atribuir la investigación del sumario en exclusiva al Fiscal, suponga la desaparición del Juez de Instrucción o del Juzgado de Guardia y debería ser entonces al Juez Penal sin perjuicio de la nueva distribución competencial en el orden jurisdiccional penal).

Defiende el principio de oportunidad reglada (concretada, delimitada) en favor del Fiscal (que opera como límite a su discrecionalidad libre) y que asuma en exclusiva la investigación sumarial, incluso pudiendo llegar a permitírsele que inicie o no el proceso penal, o que sobresea la causa (dentro de ese cauce reglado o ámbito permitido en la norma procesal penal) y sin que se tenga que abrir el juicio oral cuando además de tratarse de delitos leves no 
exista interés de la víctima en su penalización, ni de la sociedad en su persecución. Pero dicho sobreseimiento o archivo en ningún caso debería estar condicionado por conductas del sujeto pasivo investigado o imputado de concurrir el interés de la víctima o sociedad en perseguirse.

El principio de oportunidad puede servir para la determinación de la pena en caso de pronta reparación a la víctima, indemnización de los daños patrimoniales en los delitos económicos u otro tipo, escasa gravedad del hecho y perjuicio causado, escasa relevancia social, ser poco frecuente. Por tanto, que la gravedad no afecte a derechos fundamentales de la víctima como su libertad, dignidad o integridad. También la escasa edad del agresor siendo mayor de edad, la falta de antecedentes, su arrepentimiento, evitar el agresor otros efectos o consecuencias del delito en el momento de la comisión (arrepentimiento).

\section{D. NICOLÁS RODRÍGUEZ GARCÍA. (C.U. Derecho procesal de Salamanca). HACIA LA MAXIMIZACIÓN DEL PRINCIPIO DE OPORTUNIDAD DE LAS NEGOCIACIONES Y LOS ACUERDOS EN LOS PROCESOS PENALES POR CORRUPCIÓN.}

Comenzó destacando que la corrupción no puede quedar al margen del Derecho penal pues, supone una lesividad ampliada a los intereses públicos y desde el punto de vista procesal no deberían permitirse acuerdos o conformidades. El principio de oportunidad no debe operar sustituyéndose por el principio de legalidad o prever la oportunidad en su mínima expresión.

La corrupción afecta a los derechos cívicos del ciudadano, crea desigualdad entre la ciudadanía, en ocasiones por su dimensión geográfica afecta a varios Estados y puede ser un supuesto atribuible a la justicia universal (jurisdicción penal internacional). Suele formar parte del crimen organizado y con frecuencia están involucradas en la corrupción personas jurídicas a las que debe sancionarse como a sus administradores o representantes legales. Detrás de la corrupción está el sistema político, una formación política, los políticos que se dejan corromper (pasivamente) o que actúan como corruptores activamente solicitando dádivas a cambio de favores. Cuando es llevado a cabo por funcionarios además de la corrupción se puede producir un concurso real o ideal de delitos con la prevaricación. 
La corrupción supone un enriquecimiento económico con relevancia patrimonial sea activa o pasiva y debe tenderse a recobrar el producto económico del delito (decomiso) en pro del cuerpo social. Puede producirse en el ámbito público o privado (en este caso por la intervención pública). La tolerancia debe ser "cero", y para ello se exige una nueva regulación, completa y exhaustiva de cada conducta que la integra, penas más graves y que por la alarma social que conlleva se atribuya la competencia a un órgano de ámbito nacional y permitiéndose una mayor colaboración internacional en la represión de este delito dado su trasfondo muchas veces internacional.

Detrás de la corrupción existe una organización (manifestación del crimen organizado) con muchos resortes y tentáculos para blanquear los importes obtenidos y suele tratarse de un delito permanente que no se agota en un acto y con larga duración temporal hasta que se pone fin a esa organización. Debería tipificarse como un delito autónomo, pero sin olvidar que es un delito complejo (respecto a los hechos muy variados en que se manifiesta) lo que necesitaría una reforma del Código penal. Y donde se prevea la adopción de múltiples medidas cautelares o ejecutivas de contenido económico (control) destinadas a recuperar el producto económico obtenido (embargo, decomiso), y que impidan la rentabilidad del delito desde ese momento, y tendentes a facilitar su investigación y prueba con cargo a un Fiscal dotado de amplias facultades y gran experiencia (Fiscalía de la AN, Fiscalía General del Estado o Fiscalías especiales con experiencia) en cuanto cometido por una organización o grupo todo ello consecuencia de dicha corrupción. Por tanto, una profunda reforma sumarial de nuestra LECRIM.

Como se supone que la investigación por su complejidad durará mucho, debe comprobarse las medidas adoptadas durante el sumario, su prorroga y sobre todo una regulación específica que evite la prescripción de este delito.

Ello conllevaría para estos delitos una profunda reforma del proceso penal en la fase del sumario y dotar de amplias facultades al Fiscal de cara a su investigación y la adopción de tales medidas, como la creación de una especial policía judicial, crear un nuevo procedimiento especial con nueva normativa para el sumario e incluso juicio oral, mayor dotación económica destinada a la persecución de estos delitos tanto a la policía, los órganos judiciales competentes y a la propia Fiscalía.

Facilitar la colaboración ciudadana a la hora de denunciarlos, promover la labor del confidente y del arrepentido, los filtros de 
control, dotar a la policía judicial u otras policías de especialistas en informática, el papel activo de los medios de comunicación destacando la buena imagen de la ciudadanía y la administración de justicia o denunciando su papel evitando conciencias de impunidad, ajustar las garantías procesales a la complejidad del delito, justificar la verdad material en detrimento de la verdad formal a que puede conllevar el principio de oportunidad, mayor victimización social y que las víctimas sean parte en estos procesos. Fomentar la acción popular en su persecución a través de las personas físicas o las asociaciones, los grupos sociales u otras entidades, mayor control internacional en su persecución y de los procesos seguidos por corrupción.

Pero también un control sobre los jueces decisores (para evitar que puedan caer en la corrupción) es decir que dicten sentencias manifiestamente injustas (de absolutorias).

\section{EXCMO SR. D. JACOBO LÓPEZ BORJA DE QUIROGA (Magistrado del TS). EL PRINCIPIO DE OPORTUNIDAD EN EL ÁMBITO PENAL: CUESTIONES GENERALES.}

Considera que la base del principio de oportunidad está en el Derecho penal y en su injerencia sobre el particular hecho delictivo y la persona que lo comete (autor).

A medida que el delito es más grave, mayor debe ser esa injerencia del Derecho penal por ser mayor su repercusión social y estar sometido al principio de legalidad. Por el contrario, cuando el delito es de escasa gravedad menor será su repercusión social, menor esa injerencia y por ello debería permitirse el principio de oportunidad.

Esta injerencia tiene también su base en las teorías que fundamentan el Derecho penal, así las teorías retribucionistas, de la prevención individual, de la prevención social y de la rehabilitación inciden más para justificar el principio de oportunidad en Derecho penal.

En el plano del proceso penal, destaca que cuando la dirección del sumario corresponde a un órgano jurisdiccional (juez de instrucción) éste suele fundar su investigación sobre la base del principio de legalidad limitando o impidiendo los efectos derivados del principio de oportunidad. Por el contrario, cuando la dirección de la investigación sumarial, es decir la instrucción, se encomienda (por la ley procesal penal) al Fiscal se facilita o permite que dentro de las fa- 
cultades concedidas para su función tenga mayor relieve el principio de oportunidad. Sin perjuicio que las facultades encomendadas que justifican el principio de oportunidad sean discrecionales, o que por el contrario se impida o limite esta discrecionalidad controlando el principio de oportunidad por el cauce legal.

La incidencia del principio de oportunidad puede ser material a la hora de determinar la pena (más o menos grave), cambiar unas penas por otras; admitir o no excusas absolutorias, admitir o no la determinación de la prescripción de la pena, suspender el cumplimiento de la pena cumplidas las condiciones impuestas en la sentencia o que faciliten su ejecución, como es el caso de las condenas de contenido económico.

$\mathrm{O}$ puede ser procesal para que el Fiscal inicie o no el proceso penal (exigir previa denuncia, admisión del perdón determinante). O condicionarse a la importancia del interés público lesionado, a los derechos de los ciudadanos lesionados, a la alarma social. O iniciarlo para que prosiga; o se archive: Sobreseimiento. O finalice de forma extraordinaria y anticipada en caso de conformidad. Finalizado, en ejecución de sentencia el principio de oportunidad puede concretar, determinar, o suspender la sentencia o la pena. El indulto, o la amnistía (en los sistemas en que se admite) son sus manifestaciones.

\section{DÑA. MARÍA BURZACo SEMPER. (Prof. Agregada de Derecho Administrativo. Universidad Pontificia de Comillas. ICADE.) EL PRINCIPIO DE OPORTUNIDAD EN EL DERECHO ADMINISTRATIVO SANCIONADOR: SUS DERIVACIONES EN EL PROCESO CONTENCIOSO ADMINISTRATIVO.}

Inicia su intervención destacando que, en el Derecho Administrativo, el principio de oportunidad está ligado a la discrecionalidad administrativa en contraposición con el principio de reglamentación administrativa (legalidad). Supone además el principio de oportunidad un límite al control jurisdiccional.

En derecho administrativo, en el procedimiento sancionador tiene escasa incidencia el principio de oportunidad, aunque es admisible con la posible terminación convencional del mismo. $\mathrm{O}$ en caso de inacción de la Administración en la persecución de la infracción por el cauce del procedimiento administrativo sancionador. 
Las conformidades o convenios son posibles en el procedimiento administrativo sancionador antes del inicio del proceso administrativo (reclamación administrativa previa). Negociando las sanciones pecuniarias o multas impuestas por la Administración donde se pueden reducir en un importe superior al límite legal siempre que se renuncie a cualquier acción futura, o al recurso contencioso administrativo. Es discutible si ese acuerdo en este procedimiento antes del proceso contencioso administrativo responde al principio de proporcionalidad, si cumple un fin recaudatorio y por todo ello si entra dentro del principio de oportunidad.

En la legislación sectorial cada caso es diferente, y por lo general se admite la terminación anormal y convencional del procedimiento sancionador siempre con renuncia a la acción en el proceso contencioso administrativo que corresponda o en el proceso civil.

Caben también acuerdos en el proceso contencioso administrativo entre el Abogado del Estado (o de la Administración correspondiente) y el Abogado de la otra parte (del administrado o de una Administración) siempre que tengan el visto bueno de la Dirección General de lo Contencioso del Estado (o el equivalente a ésta en cada Administración) antes de la sentencia correspondiente a la instancia respectiva. En ese caso el control del juez sobre el interés público del acuerdo queda minusvalorado.

Cuando exista una resolución administrativa impugnada que afecte a terceros la publicación del acuerdo impugnado en el lugar que corresponda (BOE, BOCA, tablón de anuncios de ayuntamiento) puede suponer un límite a futuros acuerdos por parte de la Administración respecto a esos terceros que podrían ser coadyuvantes.

El principio de oportunidad incide también en la ejecución de la resolución en relación con la sanción (reducción, exoneración, sustitución, ampliar el plazo de cumplimiento).

\section{DÑA. MARTA GISBERT POMATA. (Profesora Agregada de Derecho Procesal de la Universidad Pontificia de Comillas ICADE). EL PAPEL DE LOS JUECES EN LA SOLUCIÓN NEGOCIADA DE LOS CONFLICTOS CIVILES: LA MEDIACIÓN INTRAPROCESAL.}

Aborda el principio de oportunidad en el proceso civil (asuntos civiles, mercantiles o de derecho internacional privado) como una manifestación de la autocomposición o solución negociada al con- 
flicto, se produzca antes de su iniciación o durante su pendencia. Incluso en ejecución de la sentencia.

Si es una vez iniciado caben dos conciliaciones intraprocesales a iniciativa del juez en el proceso civil común ordinario. Podrían aplicarse al juicio verbal o a los especiales.

La Unión Europea potencia las formas de solución de conflictos alternativas al proceso. Así en la Directiva 2008/52. También la Resolución del Parlamento Europeo de 13-9-2001 y la Ley 51/2012 de 6 de julio de Mediación. Hay también en este sentido un Proyecto de 16 de Enero de 2019.

Se busca potenciar en múltiples procesos, pero debe distinguirse entre aquellos que su objeto es disponible (regido por el principio dispositivo), de los que no. En los primeros los acuerdos pueden tener plena eficacia y el papel del juez debe ser más activo para lograr el acuerdo entre las partes como conciliador o mediador que es. Incluso se le puede exigir como prevé la LEC que esta iniciativa para el logro del acuerdo sea oficial. O puede ser a iniciativa de una o ambas partes y dirigirse al juez a dicho fin o intentarse fuera del proceso, aunque el acuerdo alcanzado puede producir efectos en el proceso (paralización, renuncia, desistimiento, allanamiento) sea un acuerdo procesal contenido en una resolución que recoja la transacción judicial o se trate de una transacción extrajudicial que también puede homologar el juez.

Existe incluso en el proyecto citado un intento de exigir, para iniciar procesos de ínfima cuantía, una previa mediación (equivale a la conciliación previa obligatoria antes de la reforma de la LEC de 1984) es decir una previa vinculación entre las partes para evitar el proceso, de alcanzarse el acuerdo. Pero no sólo en dichos procesos si no en los de familia, seguros, régimen económico matrimonial, derecho patrimonial de familia, acuerdos societarios, división de patrimonios, responsabilidad contractual o extracontractual, sucesiones, propiedad horizontal, derechos reales, derecho al honor, intimidad y propia imagen, propiedad intelectual, deudas hipotecarias, transporte de mercancías...

Este sistema exigirá un papel mucho más activo a los abogados de las partes, dentro de la oralidad del proceso, en la comparecencia o audiencia para que resulte decisivo (o sea, posible) el acuerdo entre las partes; y un papel más activo del juez y un cambio en su línea actual de juez espectador en el proceso dispositivo a un juez activo, director del proceso y al que la ley le exige que adopte o asuma de oficio esa función jurisdiccional. Exigirá otorgar a los procuradores 
de las partes poderes especiales para pleitos (para poder transigir), es decir para que puedan disponer, sus representados, del objeto del proceso.

\section{DÑA. DOLORES CARRILlO MÁRQUEZ. (Profesora} agregada de Derecho del Trabajo y de la Seguridad Social. Universidad Pontificia de Comillas. ICADE). REFLEXIONES SOBRE LA APLICACIÓN DEL PRINCIPIO DE OPORTUNIDAD EN LA RESOLUCIÓN DE CONFLICTOS EN EL MARCO DEL CONTRATO DE TRABAJO.

Aunque se prevé la conciliación previa obligatoria en Derecho laboral para el marco del contrato de trabajo, señala que ésta no es frecuente una vez iniciado el proceso porque el principio de legalidad se sobrepone al de oportunidad.

El objeto del proceso laboral es una materia "intervenida" y podría ser mal vista la conformidad, iniciado ya el proceso, por el desequilibrio que existe entre la defensa del empleador y la del trabajador muchas veces asumida esta última por abogados laboralistas que, a su vez, son sindicalistas. Y porque muchos ámbitos del Derecho laboral (Estatuto de los Trabajadores) defienden en dicho proceso derechos considerados indisponibles o de derecho necesario y quedarían al margen de la autonomía de la voluntad.

O son derechos ya consolidados, fruto de la negociación colectiva entre las Organizaciones empresariales y las Centrales Sindicales (convenios colectivos de marcado carácter técnico y especializado que los hace funcionar como si se tratara de "verdaderas normas") y de marcado carácter vinculante dentro de los ámbitos sectoriales.

Por tanto, iniciado el proceso estaría mal visto por el trabajador, el abogado laboralista, los propios sindicatos e incluso por los letrados de la patronal conforme a lo dicho llegar a acuerdos. Además, el contrato de trabajo es de tracto sucesivo y las soluciones negociadas de larga duración podrían ser mal vistas dentro de un mismo ámbito sectorial (v.gr sector químico, construcción...) en otros centros de trabajo.

Fuera del proceso seguido en la jurisdicción laboral existen manifestaciones del principio de oportunidad como la conciliación previa señalada, la mediación, el arbitraje, los acuerdos de las comisiones paritarias para los convenios colectivos. 


\section{DÑA. CORAZÓN MIRA ROS. (Letrada del Tribunal de Cuentas y Prof. T.U. Derecho Procesal. UNED). LA CONFORMIDAD CON LA PENA Y LOS PRINCIPIOS CONSTITUCIONALES ¿ES SIEMPRE VÁLIDA LA RENUNCIA AL DERECHO DE DEFENSA?}

Comienza destacando que debe ser un límite a la conformidad todo acto que implique una renuncia al derecho de defensa. Aunque la conformidad no suponga un reconocimiento de hechos con los efectos jurídicos del proceso civil dispositivo, al buscarse en el proceso penal la verdad real o material y no la simple verdad formal de aquél. Respecto a los efectos jurídicos que supone la conformidad sobre la pena (consecuencia jurídica penal establecida en la sentencia condenatoria o en la resolución equivalente de fondo) los límites deben venir delimitados por el Derecho penal o el Derecho procesal penal.

Debe distinguirse entre la conformidad de las personas físicas (investigado, imputado, inculpado, acusado...) y la de las personas jurídicas cuando sean parte pasiva en el mismo proceso penal (siempre que los sistemas jurídicos penales y procesales vigentes admitan su capacidad para ser responsables penalmente de forma separada e independiente de la de sus administradores o representantes legales, que son también parte pasiva en este mismo proceso penal y que la actuación del defensor de éstas o su procurador representante sea persona diferente que la que defienda y represente a aquéllos por lo que podría implicar o suponer de fraude procesal. Así se evita que la defensa y representación de los administradores y representantes legales y los de la persona jurídica, de ser los mismos, al amparo de la conformidad, echen la culpa a la persona jurídica que es parte pasiva en ese proceso penal para conseguir su total impunidad o que su pena sea menor.

En tal supuesto debería establecerse por ley que se nombrara a la persona jurídica con capacidad penal pasiva un defensor judicial dada la manifiesta contraposición de intereses entre su defensa y representación y la de sus administradores y representantes legales.

Nuestro sistema legal vigente establecido en el actual Código Penal permite la capacidad material y procesal de las personas jurídicas y por ello ser parte pasiva en el proceso penal (a diferencia con el CP precedente). Pero no reguló la LECRIM estos aspectos procesales referidos a las personas jurídicas en cuanto parte pasiva del proceso penal por tener capacidad delictiva, con lo que las dudas sobre la adecuación o no de una misma defensa y representación para la per- 
sona jurídica y sus representantes o administradores legales queda en una laguna legal a cubrir por la jurisprudencia en último término del TS como doctrina legal.

En el sistema de los anteriores Códigos penales, se seguía el sistema legal opuesto de que las personas jurídicas carecen de capacidad material criminal o punitiva, no pudiendo ser parte pasiva en el proceso penal seguido contra sus administradores o representantes legales y el único efecto legal que podía acordar la sentencia penal condenatoria en el proceso seguido contra estos era la disolución o suspensión de la persona jurídica bajo cuya actuación o "manto" se habían cometido los hechos delictivos.

Sostiene que la disolución de la persona jurídica que es parte pasiva del proceso penal (o la suspensión temporal impuesta en la sentencia penal de condena) cuando se trate de delitos económicos es posible que no sea la solución más adecuada, pues puede originar graves perjuicios económicos a la sociedad (paro a sus trabajadores que pueden no estar involucrados en ese delito y no tener ninguna culpa en su comisión, a los proveedores de esa persona jurídica o a los que provea ésta, al tejido económico, a las propias víctimas del delito, en suma a toda la sociedad). A través de la conformidad quizá se puedan establecer penas tendentes a que esa persona jurídica no vuelva a delinquir y que se eviten esos efectos económicos señalados.

Entiende que la conformidad penal (véase la intervención anterior de Luis Lafont), originaria del sistema legal angloamericano, después introducida en el sistema penal europeo, tanto para las personas físicas como jurídicas que son parte pasiva de un proceso penal en los Códigos penales y procesales penales, sobre todo tratándose de los delitos económicos debe tender a evitar el perjuicio económico a las víctimas del delito, a la reparación del daño social, a la prevención general o especial, a la defensa del interés general, la admisión de sanciones estigmatizadoras (publicidad sobre su reputación en la prensa u otros medios así en internet con destino a redes sociales) y sobre todo establecer la imposición de multas. También es importante que esa empresa en cuanto parte pasiva del proceso penal se someta a futuros programas que impidan su reincidencia y que pueden contar o prever la adopción de medidas civiles, administrativas o laborales.

También, la conformidad, sirve para aminorar la pena (caso de inmediata reparación del delito o sus efectos; colaboración de la persona jurídica con la justicia en la investigación del delito para el esclarecimiento de los hechos, revelándolos incluso si son secretos o 
concretando la responsabilidad de sus administradores o directivos; autodenuncia de los hechos constitutivos de ese delito, por la propia persona jurídica que es o puede ser parte pasiva en ese proceso; inmediato cumplimiento de la pena impuesta en la sentencia reparando a la víctima tanto en el plano moral como en el económico; escasa gravedad del delito; escaso el número de afectados; que no exista reincidencia).

O sustituyendo, con base en la conformidad, la pena inicial impuesta por otra pena o por medidas de seguridad, dentro de una cierta discrecionalidad cubierta bajo la permisión del principio de oportunidad reglada o bajo una pena indeterminada o recogida en la sentencia indeterminada penal, que se determinará en fase de ejecución, o más tarde dependiendo del comportamiento futuro de la propia persona jurídica o al amparo de una legislación penitenciaria específica (previsible para personas jurídicas).

En esa conformidad y en esas determinaciones o individualizaciones intervienen el Fiscal, el abogado de la propia persona jurídica que es parte pasiva y el juez sentenciador.

Debería distinguirse entre las personas jurídicas con capacidad delictiva según sean públicas o privadas.

Como Luis Lafont considera que su propuesta necesitaría para tener virtualidad una profunda reforma de la LECRIM y sobre todo que la investigación sumarial pasara a estar bajo la dirección del Fiscal (y no del juez de instrucción que desaparecería como tal para ocupar otros cometidos) al que se le deben confiar un amplio abanico de facultades (legales, discrecionales o bajo una discrecional reglada) que hagan posible su dirección sumarial como sucede en el sistema americano y que de allí llegó a Europa. Y en el momento oportuno, dicha conformidad entre el Fiscal y las partes del proceso penal quede bajo supervisión del órgano sentenciador. Las medidas de agilización procesal (art. 777-8 LECRIM) y de diversificación procesal pueden ser el inicio que sirva de base a la futura reforma, pero hoy siguen siendo insuficientes al objeto de lo defendido en su ponencia. 


\section{DÑA. SARA DIAZ RIAZA. (Prof. Ordinaria de Derecho Procesal. Universidad Pontificia de Comillas ICADE). MECANISMOS ALTERNATIVOS AL EJERCICIO DEL IUS PUNIENDI Y LA DESJUDICIALIZACIÓN DE LA INTERVENCIÓN CON LOS MENORES INFRACTORES.}

Su ponencia está dedicada al proceso penal de menores donde las facultades del Fiscal, por tener encomendada exclusivamente la dirección de la investigación o instrucción sumarial, son muy amplias estando regladas y sistematizadas (en la Ley reguladora del proceso de menores).

El principio de oportunidad tiene múltiples manifestaciones:

a) En las diligencias preliminares (art. 18). El fin del proceso penal del menor es reeducar y reinsertar al menor y no el fin vindicativo de la pena. Puede pues el Fiscal del menor no iniciar "el expediente" o la instrucción si existe acuerdo para adoptar medidas tendentes a ese fin.

O incoado, ponerle fin anticipadamente sin que se inicie el juicio. En esta fase sólo actúa el Fiscal. No actúa el infractor, ni la víctima, ni el juez decisor. Se exige que sean infracciones no graves, pues de serlo debe proseguir "el expediente" y abrirse el juicio y en tal caso el Fiscal asume la acusación particular.

La conformidad entre el Fiscal y la defensa del menor viene referido a la pena o a las medidas (sustitutivas) que se le imponen. La gravedad o no del hecho, su frecuencia o no, la reincidencia o no, la pronta reparación a la víctima o no, son determinantes.

b) El principio de oportunidad es un principio general informador de todo este proceso de menores. Busca evitar el proceso penal al menor y de no ser posible la terminación anticipada mediante acuerdo salvo delitos graves por él cometidos que exigen juicio.

c) El archivo está sometido al principio de legalidad y así procede el sobreseimiento libre si el hecho no es constitutivo de delito o el sobreseimiento provisional cuando no se llega a descubrir el autor.

d) Iniciadas las diligencias preliminares cabe evitar el juicio a través del desistimiento por Decreto en cuyo caso se comunica 
a la víctima para que pueda ejercitar la acción civil resarcitoria en el proceso civil. Esa conformidad manifestada en el Decreto, entre el Fiscal y la defensa del menor, sobre la pena o medidas alternativas, se asimila a una conciliación civil o mediación previa la reparación del daño.

e) Iniciado el juicio oral, (falta de conformidad o delitos graves) se dispone para el mismo de equipos técnicos especializados (prueba pericial) que asesoran al Juez de menores en cada caso concreto. Cabe la conformidad si los delitos no son graves, inclusive que los representantes legales del menor asuman compromisos que eviten ulteriores conductas delictivas del menor o reincidencia. Fuera de dichas especialidades el juicio oral del proceso de menores se asimila al proceso penal común para los delitos menos graves.

\section{ANA LUACES GUTIÉRREZ. (Prof. T.U. Derecho Procesal UNED). PROCESO DE ACEPTACIÓN POR DECRETO Y PRINCIPIO DE OPORTUNIDAD.}

Señala que fue incorporado a la vigente LECRIM por la LO 41/2015. Es un procedimiento (penal) rápido que respeta las garantías procesales comunes a todo proceso penal. Ya existía en el Derecho comparado (Alemania, Italia, Francia, Portugal), pero con variantes. Está pensado para infracciones (delitos) de poca gravedad. No es un proceso penal monitorio, como ocurre en alguna manifestación del Derecho comparado.

Notas:

- La ausencia de oposición del acusado dota de ejecutoriedad al Decreto, cuando procede.

- El Fiscal es el director de la instrucción o investigación sumarial y propone al Juez la resolución, que se comunica al investigado y si este la acepta decide el juez.

- El Fiscal durante la instrucción debe respetar todas las garantías procesales que afecten a los derechos fundamentales del investigado, sin perjuicio de la intervención del Juez para adoptar medidas que los restrinjan o limiten.

- En España, no basta con la pasividad del investigado para ser condenado, aunque acepte o manifieste su conformidad con el 
Decreto. Esto se justifica porque en el proceso penal se busca la verdad material o real a diferencia con el proceso civil dispositivo en que se busca la verdad formal.

- Este proceso, abierto el juicio oral, ante el Juez respectivo, permite terminar anticipadamente con una sentencia condenatoria de conformidad evitándose el futuro recurso ordinario de apelación. Pero la propuesta de sentencia (pena y medidas alternativas) la hace el Fiscal al Juez competente que es el Juez de Instrucción. (O el juez de violencia sobre la mujer, e incluso muy raramente el Juez central de instrucción).

- El Fiscal bajo el principio de legalidad mantiene la acusación de forma imparcial defendiendo el interés público. El abogado del acusado asume su defensa y muestra su conformidad o no con la pena propuesta en el Decreto del Fiscal. Se exige para ello que por parte de la víctima no exista acusador particular, ni tampoco acusador popular (no se haya ejercitado la acción popular), es decir no se constituyan como partes actoras en las diligencias previas bajo la instrucción del Fiscal. Considera la ponente, que si se constituyeran en partes actoras el acusador particular y el popular no se debería frustrar la propuesta del Fiscal en el Decreto cuando tanto la defensa del investigado o el imputado (parte pasiva), como las defensas del acusador particular y popular (partes actoras) estuvieran de acuerdo. Por lo demás la investigación sumarial a cargo del Fiscal es sucinta sobre los hechos y la prueba se realiza en el juicio oral con todas las garantías.

- El juicio es breve, rápido y se centra en la conformidad o no con la propuesta del Fiscal, en el Decreto. La acción civil la ejerce el Fiscal, salvo si el perjudicado se constituya o no en parte actora la reserve para el proceso civil.

- La pena en estos delitos no debe ser grave (multa, privación del permiso de circulación, trabajo en beneficio de la comunidad, reparar el daño) y con duración inferior al año. La conformidad no está pensada para penas privativas de libertad de más duración.

- El Decreto autorizado por el Juez (de instrucción o penal), evita el juicio oral, se convierte en sentencia condenatoria de conformidad. Si no lo autoriza sigue el proceso (se entra en el juicio oral) y desde ese momento el Fiscal se desvincula de su propuesta, actuando como parte acusadora conforme al principio de legalidad, salvo que se autorice finalizar antici- 
padamente el proceso en virtud de otra conformidad. Contra la sentencia condenatoria de conformidad no cabe recurso de apelación (al faltar el gravamen, presupuesto del recurso). La sentencia condenatoria (o absolutoria) dictada fuera de toda conformidad es recurrible a través del recurso ordinario de apelación.

- La ejecución de la sentencia corresponde en los delitos leves al Juez instructor y en los menos graves al Juez penal

- El ámbito de aplicación de este proceso por aceptación del Decreto es muy limitado (por el tipo de penas exigible y su duración) por lo que considera que tendrá escasa eficacia.

\section{D. CARLOS VÁzQUEZ GONZÁlES. (Prof. T.U. Derecho Penal. UNED). PRINCIPIO DE OPORTUNIDAD POLICIAL EN EL PROCESO PENAL ANGLOSAJÓN.}

Se prevé en Inglaterra y Gales respecto a hechos delictivos de poca importancia cometidos por menores. El principio de oportunidad implica que la policía (al practicar diligencias preliminares por hechos delictivos de poca entidad, cometidos por menores en ese momento o flagrantes, si no existe denuncia de la víctima, ni reincidencia), puede denunciar los hechos al Fiscal de menores para que inicie actuaciones o no denunciarlos.

Son hechos además excluidos de una medida cautelar penal (detención).

Si los denuncia al Fiscal será este quien decide si inicia o no las diligencias previas sumariales por ellos. Por supuesto que cuando la infracción es más grave tiene la obligación, la policía, de denunciarlos al Fiscal (principio de legalidad).

Si no los denuncia al Fiscal, dentro de la previsión del principio de oportunidad serán considerados tales hechos a efectos legales como un ilícito no penal, y se pone fin al expediente administrativo de la policía archivándolo contra el que no cabe recurso alguno.

El procedimiento, informal, consiste en que la policía oye al menor nada más tener conocimiento del delito cometido en ese momento, a sus representantes legales y si se trata de un simple hurto y restituye al momento el bien, o en otros delitos depone su conducta al momento (riñas tumultuarias sin lesiones y sus participantes se disuelven al instante previa petición de la policía) y se compromete 
el menor a no repetirlo y también sus representantes legales a que no lo volverá a hacer entonces la policía determina si denuncia o no. Si no lo hace se pone fin o archiva esa actuación sin más.

Si decide no denunciar la policía es efectivo el principio de oportunidad siempre que la víctima decida no denunciar. Así se pone fin a este expediente administrativo, pero no evita o impide que acuda a la vía civil el perjudicado para reclamar la indemnización por los daños causados (responsabilidad extracontractual) a los causantes.

Concluye su ponencia destacando que en España no existe esta modalidad y dirige al público del Congreso, como conclusión final, sí sería conveniente o no implantarlo en España (exclusión de la denuncia de la policía al Fiscal de menores, como principio de oportunidad tratándose de infracciones de poca entidad contra la propiedad y sin lesiones ni vulneración de otros derechos fundamentales y sin antecedentes o reincidencia del autor en delitos de ese carácter).

Por policía, para el caso español de establecerse este principio de oportunidad, se incluiría tanto la privada (de las grandes superficies) como los cuerpos de seguridad del Estado (guardia civil, policía nacional, policía judicial) autonómica (en Euzkadi y Cataluña) o local (policía municipal). Si se instaurase se aminoraría el trabajo del Fiscal y del Juez de menores. 